\title{
Lumbar spine injuries in athletes
}

\author{
Ian F. Dunn, M.D., Mark R. Proctor, M.D., and Arthur L. Day, M.D. \\ Center for Neurologic Sports Injury, and Department of Neurosurgery, Brigham and \\ Women's/Children's Hospitals, Harvard Medical School, Boston, Massachusetts
}

\begin{abstract}
$\checkmark$ Lumbar spine injuries in athletes are not uncommon and usually take the form of a mild muscle strain or sprain. More severe injuries sustained by athletes include disc herniations, spondylolistheses, and various types of fracture. The recognition and management of these injuries in athletes involve the additional consideration that to return to play, the lumbar spine must be able to withstand forces similar to those that were injurious. The authors consider common lumbar spine injuries in athletes and discuss management principles for neurosurgeons that are relevant to this population.
\end{abstract}

\section{KeY WordS • lumbar spine • spine injury • spondylolisthesis • intervertebral disc herniation $\bullet$ sports medicine}

$\mathrm{T}$ HE increased number of adults and adolescents who regularly participate in athletic activity has raised the collective awareness of common low-back injuries (bruising, overstretching, or mild to moderate tearing of the paraspinal soft tissues). A smaller percentage of injuries pose legitimate threats to the continued participation of the athlete in sport; these include such disorders as disc herniation, spondylolysis, and minor fractures. Because lumbar spine injuries usually do not affect the spinal cord, symptoms are milder, typically cause only pain and/ or single-level nerve root impingement, and continued participation in athletics is generally possible.

For the recreational athlete, from the "weekend warrior" to advanced amateur, his or her livelihood is usually obtained through means other than in the athletic arena, and cessation of play may be an unfortunate yet acceptable outcome after conservatively or surgically managed lumbar spine injury. For the elite athlete whose subsistence demands unencumbered physical performance, lumbar spine injury is a daunting prospect. The elite performer must attain an excellent functional outcome to treatment to be able to continue at the same level of performance. When surgery is required, the neurosurgeon must disturb tissue to the minimum amount necessary for a successful outcome, while remaining mindful that the athlete will continue to face the same physical stresses and dangers that were injurious in the first place. We review four common injuries to the lumbar spine in athletes (softtissue injuries, disc herniations, pars defects and their sequelae, and other minor fractures) and discuss their management and return-to-play guidelines.

\section{Epidemiological and Biomechanical Considerations}

The cumulative lifetime prevalence of low-back pain is nearly $80 \%$, with almost $30 \%$ of athletes experiencing

\footnotetext{
Abbreviations used in this paper: $\mathrm{MR}=$ magnetic resonance; $\mathrm{ROM}=$ range of motion; SPECT = single-photon emission computed tomography.
}

acute low-back pain referable to participation in sport. ${ }^{8,17}$ The type of injury varies with age; nearly $70 \%$ of lumbar spine injuries in adolescent athletes-in whom forces are exerted on skeletally immature spines-occur in the posterior elements, ${ }^{22}$ whereas the majority of low-back injuries in adult athletes are related to muscle strain and discogenic disease.

Anatomical considerations as well as the type of sport also help define an athlete's likelihood of lumbar injury. Athletes who have long trunks and particularly inflexible lower extremities are more prone to lumbar spine injury. ${ }^{5,9}$ Rehabilitation is aimed at correcting these defects when possible. Sports involving repetitive hyperextension, axial loading (and jumping), twisting, or direct contact carry higher risks of low-back injuries. The higher rates seen in football players, gymnasts, wrestlers, and rowers are supported in a study of 4790 college athletes in which the incidence of lumbar spine injury was 7\%; most were football players or gymnasts. ${ }^{14,15,20}$ Interestingly, $80 \%$ of low-back injuries occurred during practice, $14 \%$ during preseason conditioning and $6 \%$ during actual competition; a little more than $50 \%$ of these injuries were acute in nature. ${ }^{16,17}$

The forces on the lumbar motion segments are governed by the natural lordosis of this spinal segment; as a result, axial vectorial forces are directed both perpendicularly and horizontally to the disc. When the distance from the center of gravity to the spinal column is considered, the center of gravity is anterior to the lumbar spinal column, placing much of the resistive force on the erector spinae muscles, lumbodorsal fascia, and gluteus maximus. The instantaneous axis of rotation, the effective pivot point, is near the center of the disc in normal lordosis and moves posterolaterally in extension. ${ }^{25}$ Taken together, the anulus, disc, and posterior elements bear significant combinations of tensile stress and compressive and shear force, respectively, ${ }^{10,11}$ whereas the posterior soft tissues bear considerable resistive stress. These forces are found in varying degrees in all sports. 


\section{Types of Injuries}

\section{Soft-Tissue Injuries}

Muscle sprains and strains in the lumbar region are exceedingly common. The term "sprain" refers to ligamentous damage, whereas a "strain" represents an injury to a muscle, tendon, or musculotendinous junction. In the lumbar spine region, the symptoms of these types of injuries are similar and are typified by local paraspinal tenderness without radiculopathy provoked by bending, twisting, and weight bearing. Patients may report pain radiating to the hips, which may be a sign of lumbodorsal fascia spasm extending to the tensor fascia lata. Physical signs may include local bruising; significant contusions should prompt consideration of underlying transverse process fracture or renal injury, particularly if hematuria is present.

Although anteroposterior and lateral lumbar spine x-ray films may be obtained in such patients, no specific imaging is necessary. Patients are treated symptomatically with ice and/or heat, depending on the timing of the injury relative to initiation of treatment; deep tissue massage may also be helpful. Improper mechanics or inadequate stretching may predispose an athlete to soft-tissue injuries, and a fair proportion of these injuries occur during training and preseason. Appropriate rehabilitation must include the requisite mechanical adjustments and emphasis on improved strengthening of core musculature, flexibility of the lower extremities, and overall ROM. The athlete with a low-back sprain or strain can return to unrestricted competition when symptoms subside and full ROM is regained.

\section{Herniated Discs}

In many instances, symptoms related to a lumbar disc herniation begin during weight training or during a pivot or turning movement; in others, the onset is more insidious and is probably the accumulation of multiple smaller or minor injuries. Athletes exposed to considerable axial loading, flexion, and rotation, which occur during weight lifting (and sports requiring heavy lifting in competition or training), collision sports, and bowling may have higher rates of lumbar disc herniations. ${ }^{23}$ As in the general population, lumbar disc herniations are more common in older athletes. Disc herniations in adolescents, although relatively rare, do occur with sufficient frequency that this diagnosis must always be entertained. They may present more subtly with only back pain and spasm, with little or no radicular component, ${ }^{12}$ although radiculopathy still is often present. Athletes in their teens or early 20 s also frequently have less obvious signs of radiculopathy, possibly because of their youthful and supple ligamentous composition, the more viscous nature of the disc, and the lower likelihood of a free-fragment herniation.

Physical examination in the adolescent or teenager with disc herniation may only reveal mild scoliosis or unilateral hamstring tightness. In the younger group, imaging studies should be considered in patients with persistent symptoms, even though their symptoms are seemingly minor. Radiographic workup includes anteroposterior and lateral films with oblique views to visualize the pars interarticularis and lateral integrity of the spinal alignment. The MR imaging studies will delineate the anatomy of the disc and its relation to nerve roots.
Treatment decisions are more complicated in the elite athlete, because the pressure to return to play is pitted against the well-known success rates of conservatively managed lumbar disc herniations. As in all patients, absolute indications for surgery in the athlete with lumbar disc herniation include cauda equina syndrome and progressive neurological deficit; relative indications include continued pain and inability to compete in athletic competition. This last scenario merits particular consideration; the threshold for surgical intervention in the elite athlete is lower if lumbar disc herniation is a barrier to competition. If pain is considerable and there are inadequate conservative options to allow the athlete a return to performance in a timely fashion acceptable to all parties involved, surgery may be considered.

The surgical approach to the herniated lumbar disc is guided by the tenet that tissue disruption should be minimized so that the athlete may return to his or her preinjury level of physical performance. ${ }^{6}$ Barring a large central disc causing cauda equina with or without a congenitally narrow canal, bilateral laminectomies should be avoided. Either standard microsurgical discectomy ${ }^{30}$ or percutaneous microendoscopic discectomy are techniques of choice. In both techniques, a small 1.5- to $2-\mathrm{cm}$ incision is followed by fascial opening lateral to the spinous process to facilitate a tight fascial closure. This opening is followed by gentle and parsimonious paraspinous muscle dissection and enough ligamentum flavum removal and laminotomy to allow visualization of the nerve and disc fragment. Because the anulus is subjected to considerable tensile stress once competition is resumed, a wide anular opening should be avoided if possible. ${ }^{31}$

The rehabilitation program is a critical determinant to how soon the athlete can return to play, and is guided in part by the timing of the injury in relation to the athletic calendar. As always, the safety of the athlete is paramount: his or her athletic longevity and the capabilities that the player will have after his or her athletic career is ended should always be considered. A recovery program may differ if the injury is sustained at the end of a season rather than midway through. Aggressive core strengthening and increased flexibility and ROM form the basis of most programs. Athletes may return to play after a sufficient time for healing and recovery, when symptoms are minimal or absent. This decision is made jointly by the athlete and healthcare professionals. It is preferable that the athlete follow the standard course of rehabilitation after surgery, and that top-level competition only be resumed when all postoperative symptoms subside and ROM has returned so that the chance for further injury is minimized. In rare cases involving highly motivated athletes who will follow an aggressive rehabilitation program, these individuals may return to play as soon as 3 weeks postsurgery.

The following case illustrates the unique demands placed on the care of the athlete with lumbar disc herniation and the results that can be achieved with an integrated team of surgeons, trainers, and rehabilitation specialists.

Illustrative Case 1. This college All-American basketball player reported the sudden onset of severe back pain with radicular symptoms in the middle of conference play. Examination revealed mild weakness of his left extensor hallucis longus and an MR image revealed a desiccated and herniated disc at L4-5 (Fig. 1) with L-5 root impinge- 
ment. The athlete underwent surgery to expedite his return to play, which was accomplished through a minimally invasive discectomy; he recovered well and returned to full competition in conference play 3 weeks later.

\section{Pars Defects-Spondylolysis and Spondylolisthesis}

Spondylolysis and spondylolisthesis are not uncommon lumbar spine injuries in athletes, and usually occur at L-5 (L5-S1) in young athletes engaged in sports involving repetitive hyperextension and axial loading. ${ }^{4}$ Indeed, nearly $40 \%$ of athletes with back pain lasting for more than 3 months had abnormalities of the pars interarticularis in the lumbar spine. ${ }^{15}$ Football players, especially offensive and defensive linemen, and gymnasts are particularly susceptible, because both sports involve tremendous degrees of hyperextension and vertical loading. Up to $15 \%$ of college football players may have spondylolysis, ${ }^{18}$ whereas gymnasts may have an $11 \%$ incidence of spondylytic defects. ${ }^{15}$ Pars defects account for a much larger percentage of lum-

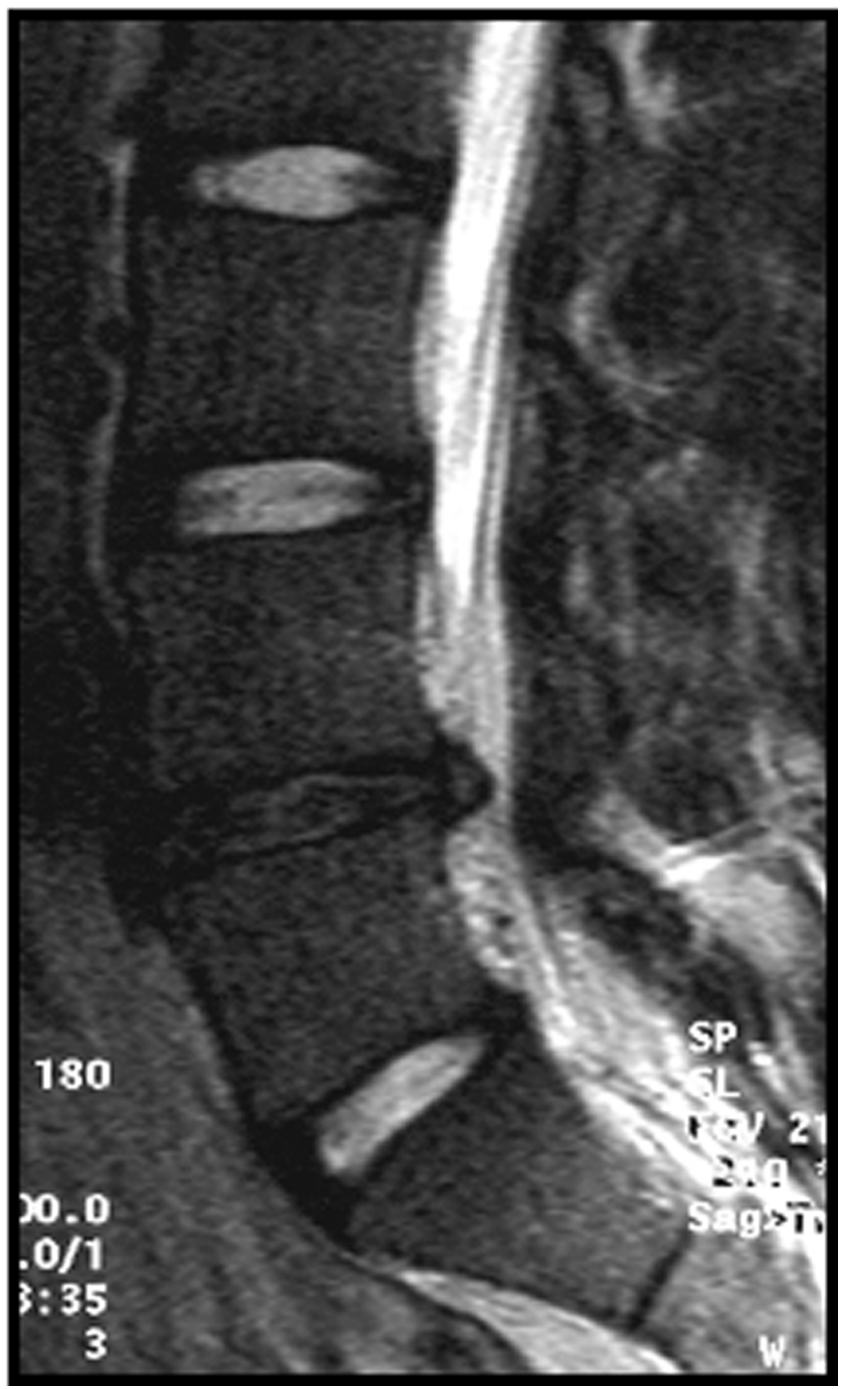

FIG. 1. Case 1. Sagittal $\mathrm{T}_{2}$-weighted MR image obtained in a collegiate basketball player with symptomatic L4-5 disc herniation. The patient underwent minimally invasive microdiscectomy and returned to play without restrictions in 3 weeks.

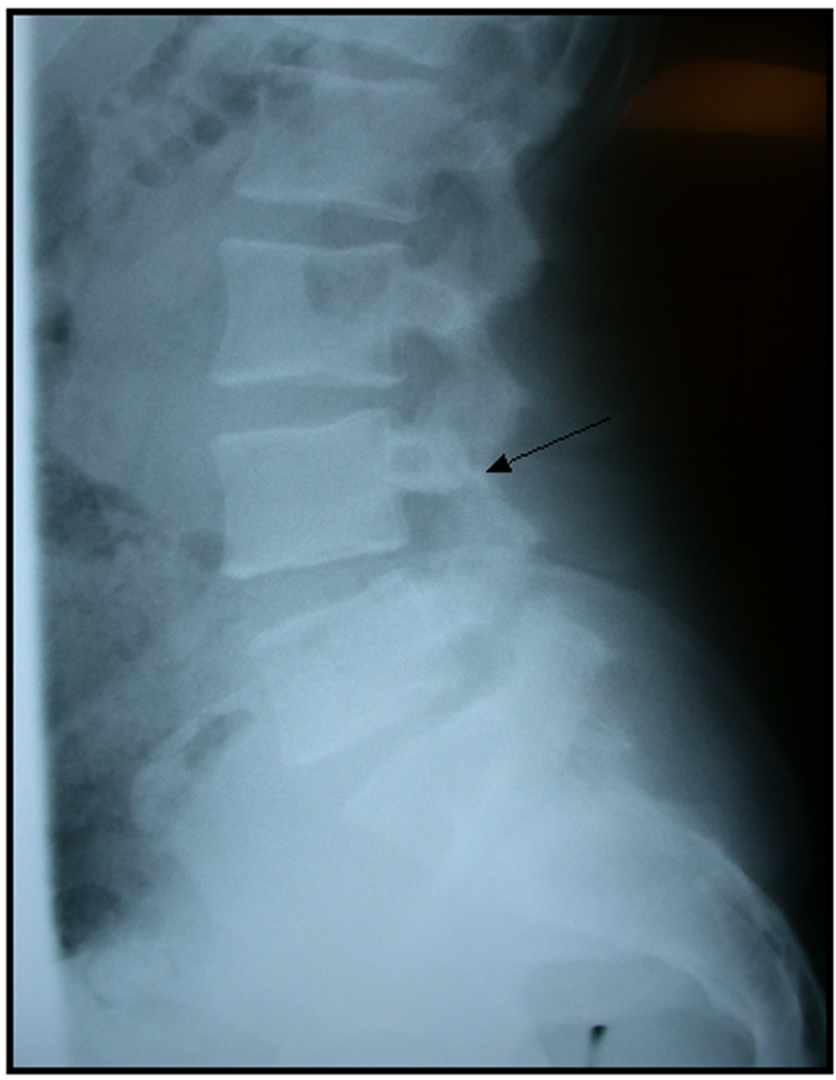

FIG. 2. Lateral plain x-ray film showing a spondyloslisthesis at L-4 (arrow).

bar spine injuries in adolescent athletes compared with adults. Children between the ages of 9 and 15 years who participate in athletic contests are at highest risk for progressive slippage. ${ }^{24}$

The presenting symptoms are low-back pain exacerbated by extension, usually without radiculopathy. Patients may compensate with knee and hip flexion on ambulation, accompanied by shortened stride (Phalen-Dickson sign). In cases of severe slippage, a slip may be palpable; otherwise, the physical examination may reveal tight hamstrings and lumbar muscle spasm.

Imaging of symptomatic lumbar hyperextension should include plain x-ray films (Fig. 2), computed tomography, and bone scanning such as SPECT scanning. ${ }^{3}$ The degree of slippage, if any, can be ascertained using plain x-ray films. Computed tomography scanning is the modality of choice to define the bone architecture of the pars. The use of SPECT scanning may enable detection of occult and acute "stress" fractures if plain X-ray films fail to reveal a defect.

The goals of management in the athlete with pars defects are alleviation of pain and prevention of progression and instability. Nonsurgical management of symptomatic pars defects depends on the degree of slippage. ${ }^{2,29}$ In patients with low-grade slips, some advocate a period of activity restriction until pain subsides, followed by gradual resumption of activity; ${ }^{13}$ should pain resume, a period of lordotic bracing (for example, a Boston brace) is recommended for between 3 and 6 months or until pain 
subsides. ${ }^{1,21,27}$ This approach may in some cases be augmented by the addition of an external bone growth stimulator, which may expedite treatment in difficult cases. ${ }^{19,26}$

Plain x-ray films should show healing of the defect by 3 months; a SPECT scan may help assess the degree of healing if plain radiographs are ambiguous. Once pain has subsided, activities focused on core muscle strengthening, lower-limb flexibility, and ROM can be resumed. Athletes with low-grade slips can usually return to competition after an aggressive rehabilitation program.

As in the nonathlete, athletes with high-grade slips, progressive slips, or symptoms refractory to conservative management are considered to be candidates for surgery. Whereas low-grade slips can be addressed by direct fusion of the pars defect, with favorable rates for the return of athletes to play in noncontact sports, ${ }^{7}$ arthrosis of the affected joint is generally performed for higher-grade spondylolisthesis. No large series of instrumented or noninstrumented spine fusion in the elite athlete exist to date, but some consider that the extent of tissue disruption, scarring, and the stress placed on adjacent structures makes the likelihood of continued postoperative pain very high, so that the athlete is unlikely to be able to return to heavy contact sports or to training at the very highest levels. ${ }^{32}$

\section{Minor Fractures}

Major fractures causing spinal instability are uncommon, except in high-speed collision sports such as auto racing and skiing. In other contact sports in which the athlete is exposed to direct blows, forceful rotation, flexion, and compression, fractures of the transverse processes, spinous processes, facets, vertebral bodies, and endplates are uncommon. Most individuals with acute fractures present with back pain immediately after the injury. In most cases, results of the neurological examination are normal.

So-called minor fractures are generally managed conservatively, because only one column is injured, so that spinal stability is not threatened. The athlete with a fracture of the transverse and/or spinous processes can resume full activity when symptoms have subsided and full ROM has returned. Mild compression fractures, not uncommon in weight lifters, can occur in the anterior aspect of the vertebral body, which lacks horizontal trabeculations. Exercises like squats or the military press involving repetitive flexion and compression of lumbar vertebral bodies may lead to endplate fracture, disc space collapse, or mild vertebral body fracture.$^{28}$ Once healing occurs, these activities must thereafter be restricted to reduce the risks of recurrence.

Fractures of the facet joints are only now becoming a recognizable entity in sports medicine, and may actually be more common than originally thought. Patients with facet fractures usually present with unilateral pain and pain on extension. In young athletes in particular, radicular symptoms may be a manifestation of an associated epidural hematoma presumably caused by bleeding from the fracture site. Recognition is important, because the injury can usually be treated conservatively and monitored with neuroimaging for resolution (Fig. 3). As with most stable fractures, athletes may return to vigorous activity when symptoms and compressive radiographic abnormalities are resolved.

Illustrative Case 2. This 15-year-old boy, a competitive
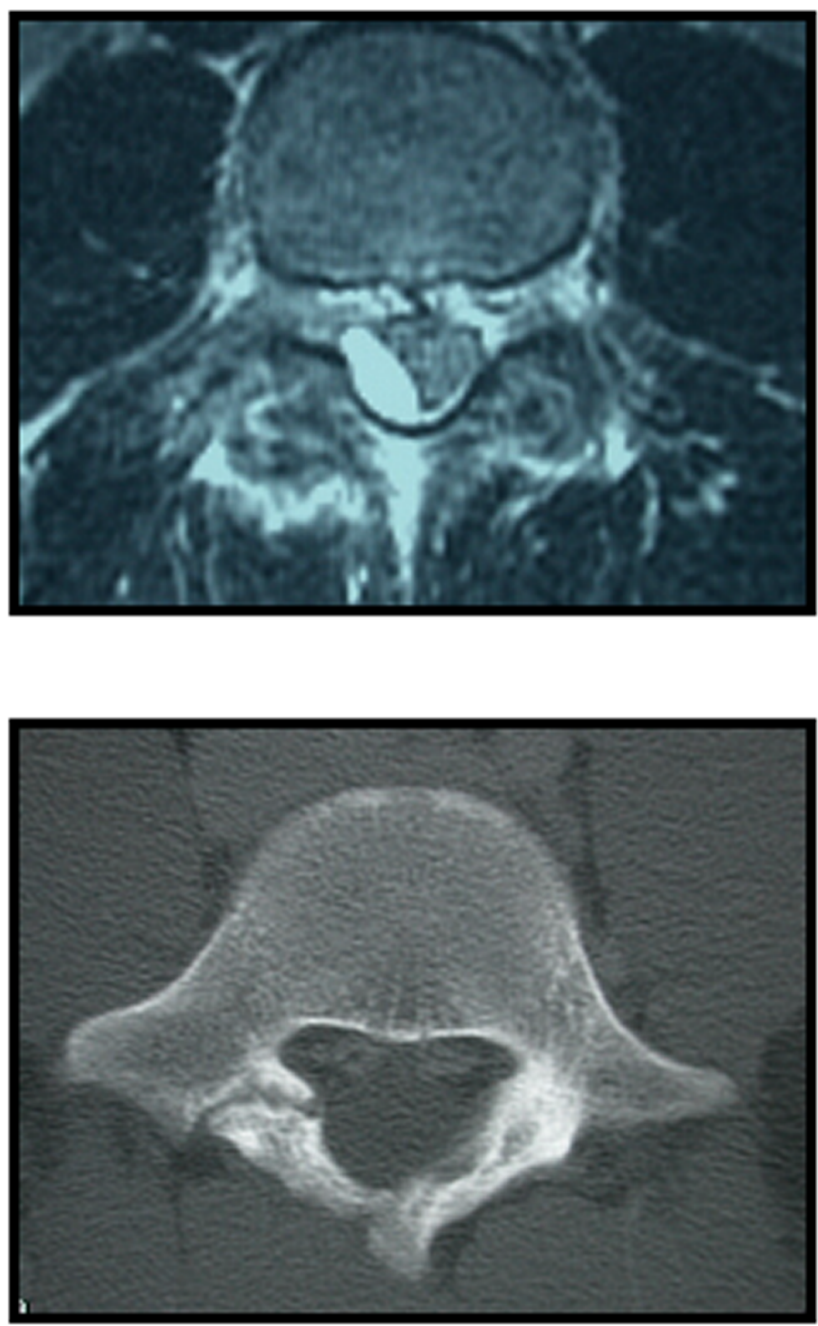

FIG. 3. Case 2. Axial MR images obtained in a patient who suffered a right facet fracture. Upper: Axial $\mathrm{T}_{2}$-weighted MR image demonstrating focal dorsolateral epidural hematoma with mild effacement of the thecal sac and root compression. Lower: Axial MR image in which spondylolysis is evident at the level of the hematoma.

baseball catcher, presented with 1 month of back pain and 1 week of severe right leg pain. He was neurologically intact on examination but had pain along the L-4 distribution; laboratory analysis of a blood sample revealed a normal erythrocyte sedimentation rate and white blood cell count. Initial MR imaging showed a right facet fracture at L-4 (Fig. 3) as well as an epidural hematoma. He was placed in a back brace and the hematoma resolved over time.

\section{Conclusions}

Athletes at all levels of competition sustain injuries to the lumbar spine. The goals of treatment include alleviation of symptoms and restoration of strength and flexibility so that full participation in sports can be resumed. When surgery is required, minimizing tissue dissection and strict adherence to an aggressive rehabilitation regimen may expedite an athlete's return to play. 


\section{References}

1. Bell DF, Ehrlich MG, Zaleske DJ: Brace treatment for symptomatic spondylolisthesis. Clin Orthop Relat Res 236:192-198, 1988

2. Blanda J, Bethem D, Moats W, Lew M: Defects of pars interarticularis in athletes: a protocol for nonoperative treatment. J Spinal Disord 6:406-411, 1993

3. Collier BD, Johnson RP, Carrera GF, Meyer GA, Schwab JP, Flatley TJ: Painful spondylolysis or spondylolisthesis studied by radiography and single-photon emission computed tomography. Radiology 154:207-211, 1985

4. Cyron BM, Hutton WC: The fatigue strength of the lumbar neural arch in spondylolysis. J Bone Joint Surg Br 60: 234-238, 1978

5. d'Hemecourt PA, Gerbino PG II, Micheli LJ: Back injuries in the young athlete. Clin Sports Med 19:663-679, 2000

6. Day AL, Friedman WA, Indelicato PA: Observations on the treatment of lumbar disk disease in college football players. Am J Sports Med 15:72-75, 1987

7. Debnath UK, Freeman BJ, Gregory P, de la Harpe D, Kerslake RW, Webb JK: Clinical outcome and return to sport after the surgical treatment of spondylolysis in young athletes. J Bone Joint Surg Br 85:244-249, 2003

8. Dreisinger TE, Nelson B: Management of back pain in athletes. Sports Med 21:313-320, 1996

9. Fairbank JC, Pynsent PB, Van Poortvliet JA, Phillips H: Influence of anthropometric factors and joint laxity in the incidence of adolescent back pain. Spine 9:461-464, 1984

10. Farfan HF: The biomechanical advantage of lordosis and hip extension for upright activity. Man as compared with other anthropoids. Spine 3:336-342, 1978

11. Farfan HF: Muscular mechanism of the lumbar spine and the position of power and efficiency. Orthop Clin North Am 6: 135-144, 1975

12. Gerbino PG II, Micheli LJ: Back injuries in the young athlete. Clin Sports Med 14:571-590, 1995

13. Harvey J, Tanner S: Low back pain in young athletes. A practical approach. Sports Med 12:394-406, 1991

14. Hoshina H, Yoshii A, Kitamura M, Kashiwazaki S: [Studies on clinical significance and pathogenesis of calcinosis in progressive systemic sclerosis (author's transl).] Nippon Naika Gakkai Zasshi 69:723-731, 1980

15. Jackson DW: Low back pain in young athletes: evaluation of stress reaction and discogenic problems. Am J Sports Med 7: 364-366, 1979

16. Keene JS, Albert MJ, Springer SL, Drummond DS, Clancy WG Jr: Back injuries in college athletes. J Spinal Disord 2: 190-195, 1989

17. Kelsey JL, White AA III: Epidemiology and impact of lowback pain. Spine 5:133-142, 1980
18. McCarroll JR, Miller JM, Ritter MA: Lumbar spondylolysis and spondylolisthesis in college football players. A prospective study. Am J Sports Med 14:404-406, 1986

19. McTimoney CA, Micheli LJ: Current evaluation and management of spondylolysis and spondylolisthesis. Curr Sports Med Rep 2:41-46, 2003

20. Micheli LJ: Back injuries in gymnastics. Clin Sports Med 4: 85-93, 1985

21. Micheli LJ, Hall JE, Miller ME: Use of modified Boston brace for back injuries in athletes. Am J Sports Med 8:351-356, 1980

22. Micheli LJ, Wood R: Back pain in young athletes. Significant differences from adults in causes and patterns. Arch Pediatr Adolesc Med 149:15-18, 1995

23. Mundt DJ, Kelsey JL, Golden AL, et al: An epidemiologic study of sports and weight lifting as possible risk factors for herniated lumbar and cervical discs. The Northeast Collaborative Group on Low Back Pain. Am J Sports Med 21: 854-860, 1993

24. Muschik M, Hahnel H, Robinson PN, Perka C, Muschik C: Competitive sports and the progression of spondylolisthesis. J Pediatr Orthop 16:364-369, 1996

25. Pearcy MJ, Bogduk N: Instantaneous axes of rotation of the lumbar intervertebral joints. Spine 13:1033-1041, 1988

26. Pettine KA, Salib RM, Walker SG: External electrical stimulation and bracing for treatment of spondylolysis. A case report. Spine 18:436-439, 1993

27. Steiner ME, Micheli LJ: Treatment of symptomatic spondylolysis and spondylolisthesis with the modified Boston brace. Spine 10:937-943, 1985

28. Stinson JT: Spine problems in the athlete. Md Med J 45: 655-658, 1996

29. Sys J, Michielsen J, Bracke P, Martens M, Verstreken J: Nonoperative treatment of active spondylolysis in elite athletes with normal X-ray findings: literature review and results of conservative treatment. Eur Spine J 10:498-504, 2001

30. Wang JC, Shapiro MS, Hatch JD, Knight J, Dorey FJ, Delamarter RB: The outcome of lumbar discectomy in elite athletes. Spine 24:570-573, 1999

31. Watkins RG: Lumbar disc injury in the athlete. Clin Sports Med 21:147-165, 2002

32. Wright A, Ferree B, Tromanhauser S: Spinal fusion in the athlete. Clin Sports Med 12:599-602, 1993

Manuscript received August 21, 2006.

Accepted in final form September 7, 2006.

Address reprint requests to: Arthur L. Day, M.D., Department of Neurosurgery, Brigham and Women's Hospital, 75 Francis Street, Boston, Massachusetts 02115. email: aday1@partners.org. 